\title{
RESPONSE TO COMMENTS
}

\section{Archaeology vs. Archaeological Science}

\section{Kerstin Lidén \& Gunilla Eriksson}

We are grateful to the commentators for their valuable and insightful contributions, and thank them for their thought-provoking comments. We find joy in the descriptions of archaeology as a discipline with crossover potential, inherently collaborative, interdisciplinary and "messy", and cannot but agree with Andrew Jones that archaeology is fun! But what follows from these characteristics is also what makes archaeology so challenging, and sometimes even difficult.

Several of the commentators have identified one of the roots of this difficulty: the education system. There are obviously considerable differences between countries, especially in the higher education system. As for archaeology programmes, most UK universities seem to offer courses in archaeological science, whereas this is not the case in Norway and Sweden. This could be easily solved by integrating a mandatory element of archaeological science into the curricula of archaeology courses at all levels.

What is obvious when reading through the comments is that we all take our own realities as starting points - that was certainly our starting point. This is particularly evident when it comes to what we refer to as the filter. Although not all of the commentators admit to having personally encountered or practised the filter, it does seem to exist in various countries. And it could be expressed differently within different fields of archaeology. 
Regarding the privilege of interpretation, we definitely agree with Stephen Shennan that it is not Jared Diamond's fault that he got the attention he did for Guns, Germs and Steel. Instead, we as archaeologists have to stand up to the challenge of presenting a coherent story of our past, and not simply give away the privilege of interpretation.

Most of the commentators also agree that the difficulties can be overcome by collaboration. Here we want to emphasize that this should be true collaborative work, where the integration of different disciplines is present already at the planning stage of a research study, and where all parties involved have a "flexible attitude and openness to new ways of thinking" (cf. Hamilton et al. 2009:I83), while maintaining discipline integrity. This means that both the scientific methods and the archaeological models, along with the preconceptions that follow from these, should be scrutinized and valued in the same way, as Åsa Larsson suggests, or, as Jones states, "there is a need for a symmetrical approach in evaluating the scientific analytical results and the theoretical interpretation". There is frequently a great need for cultural history in the more science-oriented studies, just as more scientific methods could be justified in the more cultural-history oriented studies, as stressed by both Christopher Prescott and Johannes Müller.

To conclude, there seems to be a consensus regarding the need to get rid of the filter, by enhanced communication between the different communities. We work hard on eliminating any filters, and we firmly believe in the benefits for archaeology of true collaborative work; interdisciplinary conversation is not Utopia.

Kerstin Lidén \& Gunilla Eriksson
Archaeological Research Laboratory,
Department of Archaeology and Classical Studies,
Stockholm University
SE-I06 91 Stockholm
Sweden

\section{REFERENCES}

Hamilton, A., Watson, F., Davies, A. L. \& Hanley, N. 2009. Interdisciplinary Conversations: The Collective Model. In: Sörlin, S. \& Warde, P. (Eds). Nature's End: History and the Environment. Pp. I62-I87. Houndmills, Basingstoke: Palgrave Macmillan. 